Session 1547

\title{
Simulation for the study of beam deflection in strength of materials
}

\author{
Alamgir Choudhury \\ Western Michigan University \\ Christian Ochei \\ Robert Rice \\ Cuyahoga Community College
}

\begin{abstract}
The diversity of student background in two-year institutions is a limiting factor in realizing the course objectives of the strength of materials class. Specifically, teaching beam deflection theory has been difficult and time consuming in the traditional manner. Instead of focusing on only theory and routine problem solving techniques in the class, the introduction of beam deflection simulation and computer programming generates student interest in the subject. Visual input from the graphical simulation draws student attention to the underlying cause of deflection and eventual comprehension of the theory. By studying the effects of beam characteristics and loading conditions on the nature of the deflection curve, students develop insight on deflection and its parameters. Flexible instruction material is developed on how to use existing deflection tools as well as create similar application programs. Simultaneous study of deflection theory, practice of exercise problems and experimentation with deflection simulation have improved student learning in the area. This simulation and programming task replaces previous laboratory experiment on wooden beam deflection. Therefore, curriculum objectives are achieved without utilizing additional laboratory time.
\end{abstract}

\section{Introduction}

At Cuyahoga Community College (CCC), Strength of Materials is a required course for the mechanical engineering technology and architecture/construction technology programs. Beam deflection theory and the associated exercise problems are an indispensable part of a traditional strength of materials curriculum in similar programs. The subject is taught using both moment-area and superposition methods [1,2]. While the moment-area method uses properties of bending moment diagram area, the superposition technique requires the combined use of existing deflection equations for standard component problems. Though the moment-area technique can be used to solve statically determinate deflection problems in general, the mathematics involved with the process may be burdensome for average students. In the superposition method, the deflection problem is divided into several sub-problems, whose deflection equations are presented in the superposition chart [1]. Successful use of the technique requires correct 
development of the sub-problems and the existence of their deflection equations in the chart. In some cases development of the sub-problems requires significant experience and can be difficult for many students. Past experience in the classroom indicates that the average students at CCC tend to avoid the use of the moment-area technique mainly because of its detailed mathematical nature and prefer the superposition method. During the past decade, the introduction of computer usage has significantly reduced manual computation requirements in many engineering technology classes. In the strength of materials class, the objectives of computer use are:

(i) Minimize manual computations.

(ii) Facilitate understanding of theory.

(iii) Generate student interest in the subject matter.

(iv) Develop confidence in computer usage for solving technical problems and consequently enhance student skill in a programming language.

The project is comprised of three phases, two of which have already been implemented. In the first phase, students are taught the step-by-step programming for solving example problems in the class. In phase two, students write their own programs to simulate deflection of a given beam problem as laboratory exercise. The tool for the third phase has recently been developed and will be introduced in class during fall semester 2001. Using this tool, students will be able to compare analytical solutions of their homework problems with deflection produced by a computer program.

Similar tools were developed in various schools in the past [3, 4, 6, 8]. Ressler [3] developed "Visual Stress Transformer," a Visual Basic program to animate stress transformation in strength of materials class. Jong and Onggowijaya [5] used Qbasic [6] programming language to simulate four-bar linkage motion in a kinematics class. Others $[7,8,10]$ used available commercial software such as Working Model [4] and Spreadsheet either to enhance student learning or to teach students computer applications for solving technical problems. The tool presented here was developed based on the objectives (i)-(iv) outlined above.

The graphics feature available in Visual Basic is suitable for the visual display of deflection calculation. The Visual Basic programming class is also required for graduation in any engineering technology program at CCC. Therefore, Visual Basic is most appropriate as the programming language for the project. This also allows us to implement the project without spending time in teaching the programming language. For students with different backgrounds, programming in Qbasic or C++ is equally encouraged. It is already evident from student grades that their understanding of beam deflection has improved.

\section{Student background}

$\mathrm{CCC}$ is an open-door urban community college with a large diverse student population. Students enrolling in the strength of materials class pursue a two-year associate degree either in mechanical engineering technology or architecture/construction technology. 
Student diversity in the programs arises from socio-economic background, age, prior education, aptitude level, math-science background and educational objective. About one third of the students are regular high school graduates while others are working full or part time and returning to school after a break in study. A significant number of these students take only certain classes to enhance their skill in specific areas for professional enhancement. Therefore, at CCC, in any curriculum or teaching-tool development, flexibility is crucial in achieving broader student success.

\section{Previous method}

At CCC, the strength of materials is a three-hour semester course. Beam deflection is covered over a two-week period in a total of eight hours of lecture and laboratory. In the past, the task consisted of lecture, problem solving, laboratory exercise and lab report writing. The topics were covered in sequence of

(i) Deflection theory

(ii) Deflection calculation by using bending moment diagram area

(iii) Deflection calculation by superposition method

(iv) Laboratory experiment to verify deflection versus load relationship in a simply supported wooden beam.

The average student's performance was generally poor in this area, especially, in part (ii) of the sequence. Many students tried to avoid this part of the course because of the extensive computation required in the method.

\section{New method}

Recently, the newer textbooks come with the programming tools that can be used to calculate deflection in a specific beam problem. Some texts also include application program development examples. Because of the broad objective of this project, we required a more comprehensive tool that could achieve all the goals outlined in section 1. The project is implemented in three phases, namely, (a) application program development lesson, (b) laboratory exercise and (c) use of a general programming tool.

\subsection{Application program development lesson}

At the beginning of this step an example problem is analyzed in the class by using both moment-area and superposition methods. Next, based on the deflection equations already developed, the step-by-step procedure for development of a simple Visual Basic program for the example problem is taught. For most students with Visual Basic background, learning of such programming comes naturally. To maintain flexibility for students with weaker programming backgrounds, such program development lessons in Qbasic are also made available. The Qbasic version of an example program is shown in Figure 1. By executing the program for various deflection parameters, e.g. moment of inertia of beam cross section, modulus of elasticity of material and magnitude, nature and location of 
load, students can also study the effect of these parameters on nature of deflection curve and magnitude of deflection. Besides visualization, such experimentation also helps students develop intuition on the nature of deflection and effects of beam parameters on deflection. In absence of such tools similar outcomes would be achieved only after extensive practice.

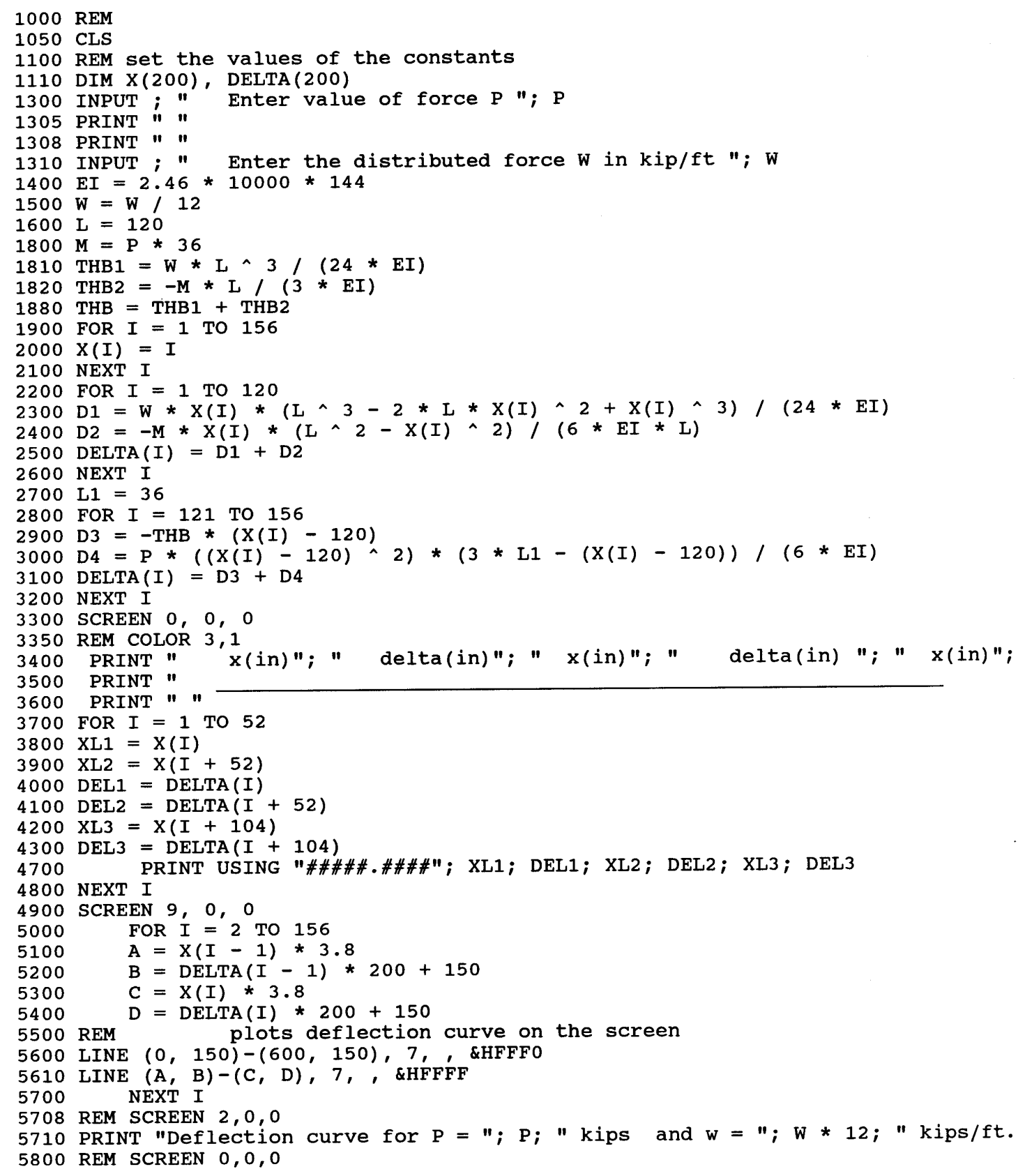

Figure 1

Qbasic version of an example program 


\begin{tabular}{|c|c|c|c|c|c|}
\hline$x$ (in) & delta (in) & $x($ in $)$ & delta (in) & $x($ in $)$ & delta (in) \\
\hline 1.0000 & 0.0060 & 53.0000 & 0.2084 & 105.0000 & 0.0633 \\
\hline 2.0000 & 0.0121 & 54.0000 & 0.2087 & 106.0000 & 0.0587 \\
\hline 3.0000 & 0.0181 & 55.0000 & 0.2090 & 107.0000 & 0.0542 \\
\hline 4.0000 & 0.0241 & 56.0000 & 0.2090 & 108.0000 & 0.0496 \\
\hline 5.0000 & 0.0300 & 57.0000 & 0.2090 & 109.0000 & 0.0452 \\
\hline 6.0000 & 0.0360 & 58.0000 & 0.2087 & 110.0000 & 0.0407 \\
\hline 7.0000 & 0.0419 & 59.0000 & 0.2084 & 111.0000 & 0.0363 \\
\hline 8.0000 & 0.0477 & 60.0000 & 0.2078 & 112.0000 & 0.0320 \\
\hline 9.0000 & 0.0536 & 61.0000 & 0.2071 & 113.0000 & 0.0277 \\
\hline 10.0000 & 0.0593 & 62.0000 & 0.2063 & 114.0000 & 0.0235 \\
\hline 11.0000 & 0.0651 & 63.0000 & 0.2053 & 115.0000 & 0.0193 \\
\hline 12.0000 & 0.0707 & 64.0000 & 0.2042 & 116.0000 & 0.0153 \\
\hline 13.0000 & 0.0763 & 65.0000 & 0.2029 & 117.0000 & 0.0113 \\
\hline 14.0000 & 0.0818 & 66.0000 & 0.2015 & 118.0000 & 0.0074 \\
\hline 15.0000 & 0.0873 & 67.0000 & 0.1999 & 119.0000 & 0.0037 \\
\hline 16.0000 & 0.0927 & 68.0000 & 0.1982 & 120.0000 & -0.0000 \\
\hline 17.0000 & 0.0980 & 69.0000 & 0.1964 & 121.0000 & -0.0035 \\
\hline 18.0000 & 0.1032 & 70.0000 & 0.1944 & 122.0000 & -0.0069 \\
\hline 19.0000 & 0.1083 & 71.0000 & 0.1923 & 123.0000 & -0.0102 \\
\hline 20.0000 & 0.1133 & 72.0000 & 0.1900 & 124.0000 & -0.0134 \\
\hline 21.0000 & 0.1183 & 73.0000 & 0.1877 & 125.0000 & -0.0165 \\
\hline 22.0000 & 0.1231 & 74.0000 & 0.1852 & 126.0000 & -0.0195 \\
\hline 23.0000 & 0.1278 & 75.0000 & 0.1825 & 127.0000 & -0.0223 \\
\hline 24.0000 & 0.1324 & 76.0000 & 0.1798 & 128.0000 & -0.0251 \\
\hline 25.0000 & 0.1369 & 77.0000 & 0.1769 & 129.0000 & -0.0278 \\
\hline 26.0000 & 0.1413 & 78.0000 & 0.1739 & 130.0000 & -0.0304 \\
\hline 27.0000 & 0.1456 & 79.0000 & 0.1708 & 131.0000 & -0.0329 \\
\hline 28.0000 & 0.1497 & 80.0000 & 0.1676 & 132.0000 & -0.0353 \\
\hline 29.0000 & 0.1538 & 81.0000 & 0.1643 & 133.0000 & -0.0376 \\
\hline 30.0000 & 0.1577 & 82.0000 & 0.1609 & 134.0000 & -0.0399 \\
\hline 31.0000 & 0.1615 & 83.0000 & 0.1574 & 135.0000 & -0.0420 \\
\hline 32.0000 & 0.1651 & 84.0000 & 0.1537 & 136.0000 & -0.0442 \\
\hline 33.0000 & 0.1686 & 85.0000 & 0.1500 & 137.0000 & -0.0462 \\
\hline 34.0000 & 0.1720 & 86.0000 & 0.1462 & 138.0000 & -0.0482 \\
\hline 35.0000 & 0.1752 & 87.0000 & 0.1424 & 139.0000 & -0.0501 \\
\hline 36.0000 & 0.1783 & 88.0000 & 0.1384 & 140.0000 & -0.0519 \\
\hline 37.0000 & 0.1813 & 89.0000 & 0.1344 & 141.0000 & -0.0537 \\
\hline 38.0000 & 0.1841 & 90.0000 & 0.1302 & 142.0000 & -0.0555 \\
\hline 39.0000 & 0.1868 & 91.0000 & 0.1261 & 143.0000 & -0.0572 \\
\hline 40.0000 & 0.1893 & 92.0000 & 0.1218 & 144.0000 & -0.0589 \\
\hline 41.0000 & 0.1917 & 93.0000 & 0.1175 & 145.0000 & -0.0605 \\
\hline 42.0000 & 0.1939 & 94.0000 & 0.1132 & 146.0000 & -0.0621 \\
\hline 43.0000 & 0.1960 & 95.0000 & 0.1088 & 147.0000 & -0.0636 \\
\hline 44.0000 & 0.1979 & 96.0000 & 0.1043 & 148.0000 & -0.0651 \\
\hline 45.0000 & 0.1997 & 97.0000 & 0.0998 & 149.0000 & -0.0666 \\
\hline 46.0000 & 0.2013 & 98.0000 & 0.0953 & 150.0000 & -0.0681 \\
\hline 47.0000 & 0.2028 & 99.0000 & 0.0908 & 151.0000 & -0.0695 \\
\hline 48.0000 & 0.2041 & 100.0000 & 0.0862 & 152.0000 & -0.0710 \\
\hline 49.0000 & 0.2053 & 101.0000 & 0.0816 & 153.0000 & -0.0724 \\
\hline 50.0000 & 0.2063 & 102.0000 & 0.0771 & 154.0000 & -0.0738 \\
\hline 51.0000 & 0.2071 & 103.0000 & 0.0725 & 155.0000 & -0.0752 \\
\hline 52.0000 & 0.2078 & 104.0000 & 0.0679 & 156.0000 & -0.0766 \\
\hline
\end{tabular}

Deflection for $P=12$ kips and $w=5 \mathrm{kips} / \mathrm{ft}$.

Table I

Deflection table for an example problem

Proceedings of the 2001 American Society for Engineering Education Annual Conference \& Exposition Copyright $(\odot)$ 2001, American Society for Engineering Education 


\subsection{Laboratory exercise}

This part of the process replaces the old laboratory exercise on deflection measurement of a wooden beam due to transverse load. Instead, individual students are required to develop an application program to simulate deflection of a given beam problem. Figure 2 and 3 show a typical problem and the corresponding output. The problem is generally similar to the example presented in section 4.1 and requires a clear understanding prior to this new program development. Students who have taken the computer-programming class before fall semester 1998 are familiar with Qbasic instead of Visual Basic programming language. They develop their lab program based on the Qbasic version of the example program presented in section 4.1. During the final week students make class presentations of their work. The outcomes are often mixed. Above-average students generally develop innovative programs and present deflection of the beam under various loading conditions using impressive multimedia effects. Students with weaker academic and computer backgrounds attempt to modify the example program of section 4.1 to present their solutions. Nevertheless, compared to the old method, the new technique achieves our learning objectives better.

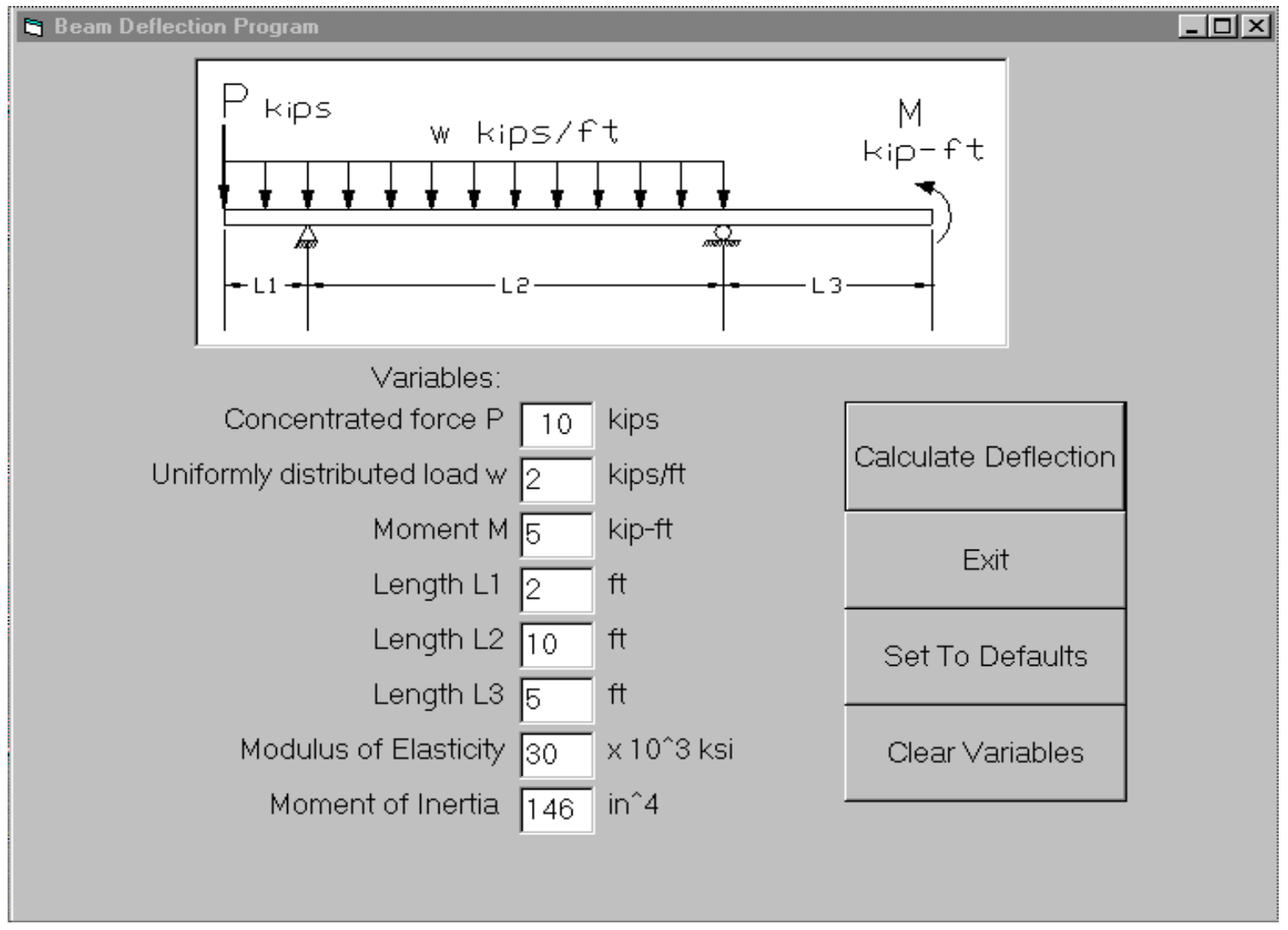

Figure 2

Typical laboratory exercise problem 


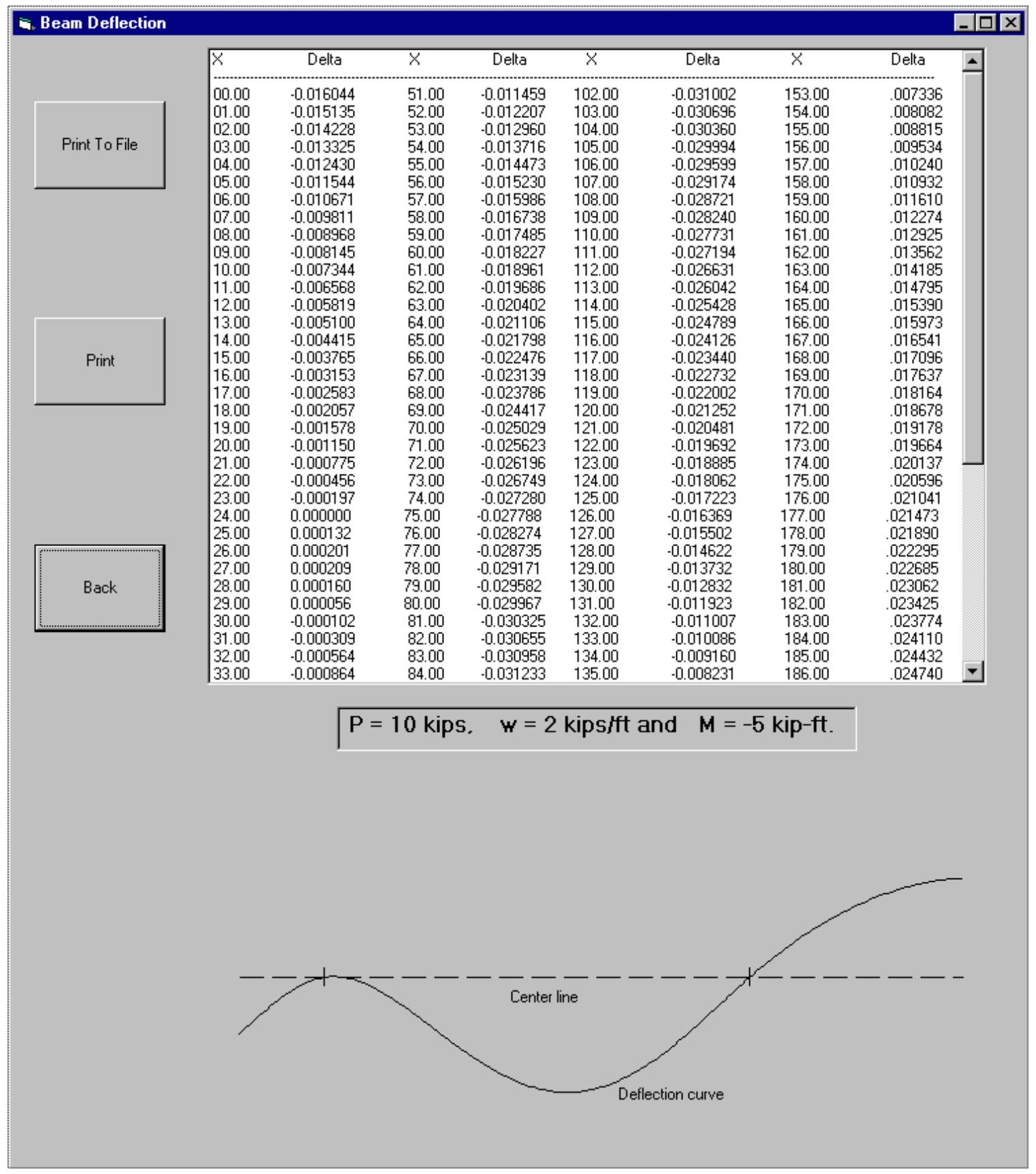

Figure 3

Typical output of a Visual Basic laboratory problem

\subsection{General programming tool}

This Visual Basic program has been developed recently for students to verify deflection calculations of most homework assignments. An executable file created from the general Visual Basic deflection program will be available for student use. Therefore, use of this program does not require prior programming experience, and students can familiarize

Proceedings of the 2001 American Society for Engineering Education Annual Conference \& Exposition Copyright (C) 2001, American Society for Engineering Education 
themselves with the use of this program quickly in a single class presentation. The beams can be simply supported, cantilever, or over hanging. The beam geometry and load characteristics are shown in Figure 4, 5 and 6 below. Based on the selection, appropriate beam deflection parameters would be specified. These are lengths, moment of inertia of cross section, modulus of elasticity, magnitude and locations of concentrated/distributed loads and external moment. To solve the problem, students will simply specify beam geometry and loading parameters and run the program. The output will be in the form of a table for deflection versus distance from one end of the beam and corresponding deflection curve. If the analytical solutions produced by the students differ from the computer output, students would be required to locate the source of error in their calculations until the two solutions match. The program will not allow solution of the laboratory problem, which is generally overhanging in one side only.

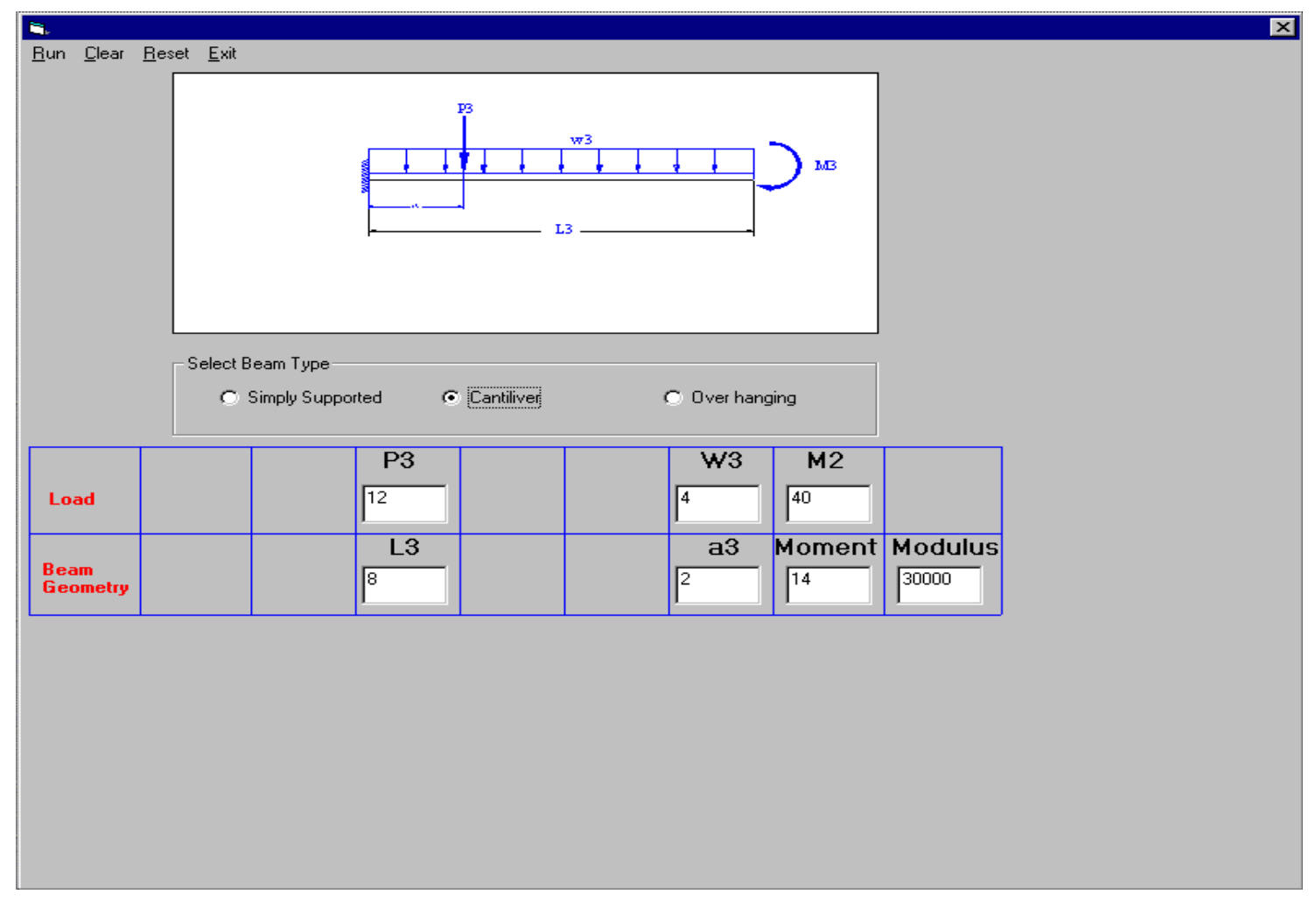

Figure 4

Cantilever beam problem

\section{Measurement of student outcomes}

All engineering technology programs in $\mathrm{CCC}$ have developed a plan for student outcomes assessment. Currently the data for such assessment are being collected from various sources in specific cycles. Analysis of these data relevant to strength of materials class will provide quantitative measurement of student learning improvement due to use of the tool presented here. 


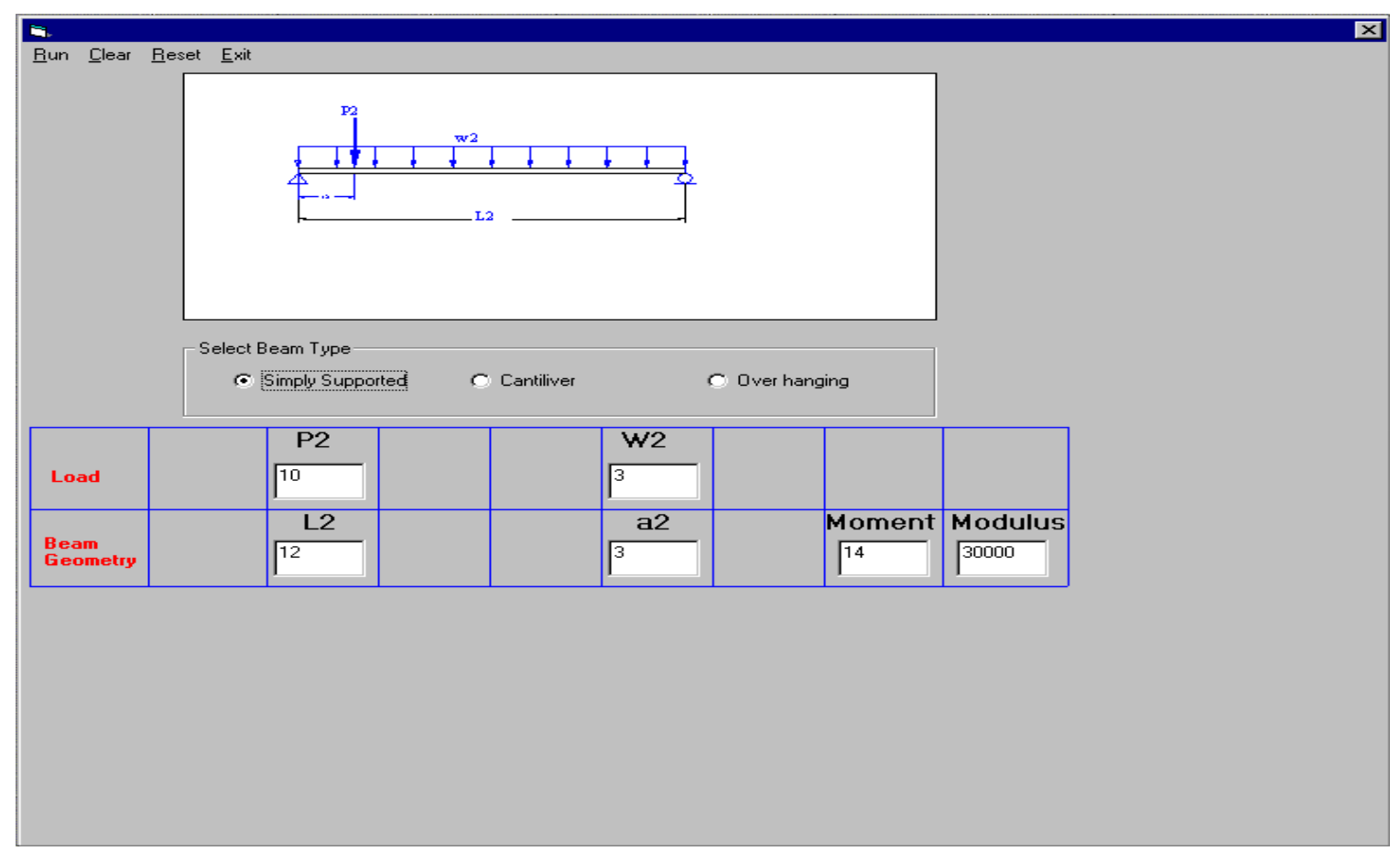

Figure 5

Simply supported beam problem

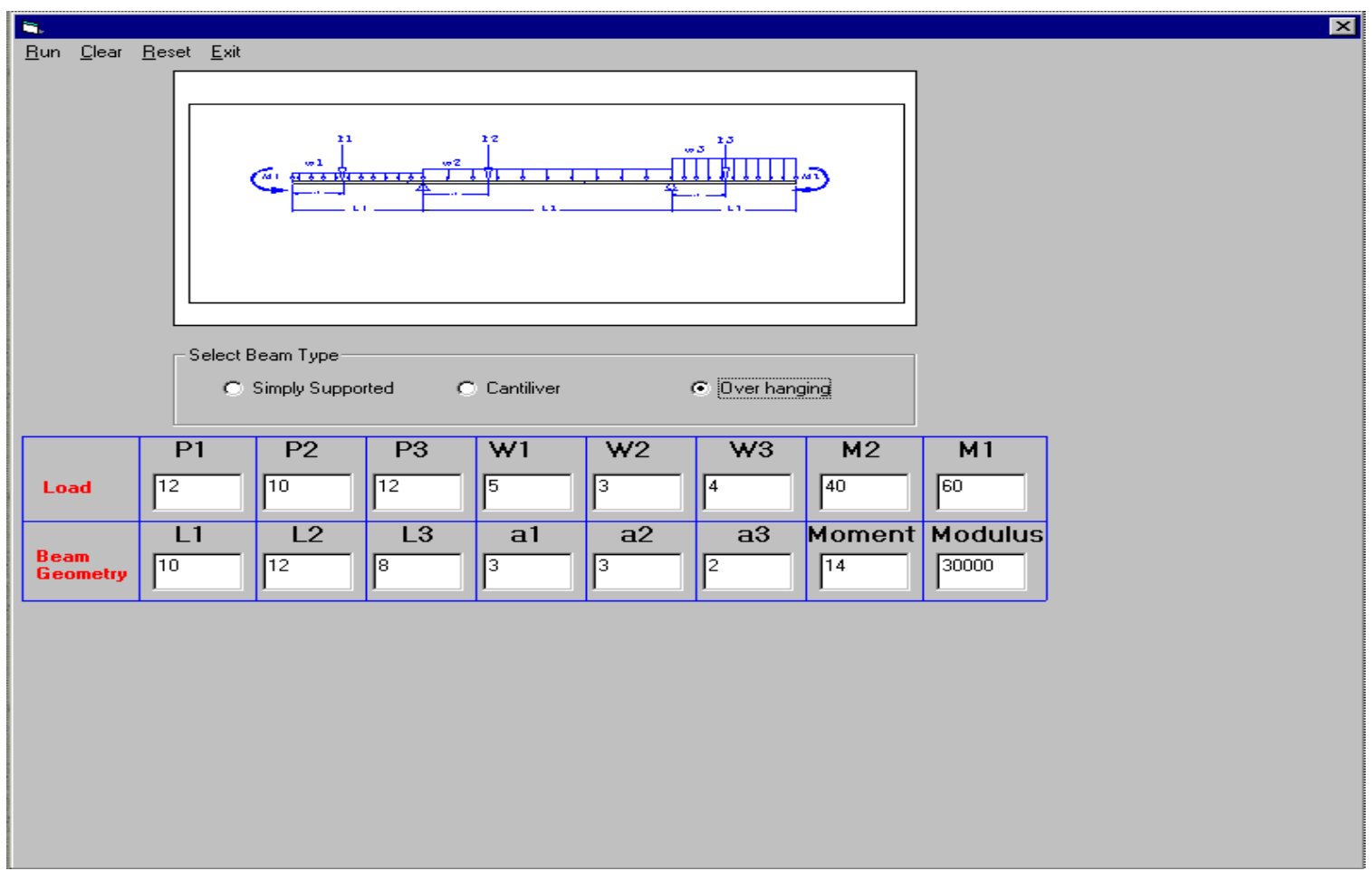

Figure 6

Overhanging beam problem

Proceedings of the 2001 American Society for Engineering Education Annual Conference \& Exposition Copyright (C) 2001, American Society for Engineering Education 


\section{Conclusion}

The tool presented here is designed to facilitate learning of beam deflection theory in the strength of materials class and build student confidence in the development and use of computer program for solving deflection problems. We feel that use of commercial software for such lessons would neither be cost effective nor generate similar interest in the subject matter. The MET advisory committee highly recommends use of this tool for teaching beam deflection.

\section{Bibliography}

1. Cheng; Hwa-Fa, Statics and Strength of Materials, Glenco/Mc-Graw Hill, 1997.

2. $\quad$ Mott; Robert L., Applied Strength of Materials, Prentice Hall Inc., 1996.

3. Ressler; Stephen, The visual stress transformer: An animated computer graphics program for engineering mechanics education, ASEE conference proceeding, 1996.

4. Working Model, Knowledge Revolution Inc., San Mateo, CA, 1998.

5. Jong; I., Onggowijaya; S., Animated programming with QuickBASIC to aid the teaching kinematics, ASEE conference proceeding, 1998.

6. Microsoft Qbasic Bible, Microsoft Press, Richmond, WA, 1990.

7. Kumar; Ratan, Teaching dynamics in engineering technology through software tools, ASEE conference proceeding, 1998.

8. Boronkay; T, Earley; R, Simulation software in a dynamics laboratory, ASEE conference proceeding, 1998.

9. $\quad$ Sprague, M., Using Visual Basic, South-Western Educational Publishing, 1997.

10. Prusak; Zbigniew, Simulation using spreadsheets in the engineering technology curriculu satisfying multiple learning objectives, ASEE conference proceeding, 1999.

\section{ALAMGIR CHOUDHURY}

Alamgir A. Choudhury taught engineering technology at Cuyahoga Community College, Cleveland, Ohio, since 1990. He has BS, MS and PhD in mechanical engineering. His interest includes computer applications in curriculum, MCAE, instrumentation, fluid power and mechanics. He is also a Registered Professional Engineer in the State of Ohio and affiliated with ASME, ASEE and TAP. Currently he is teaching at Western Michigan University, Kalamazoo, Michigan.

\section{CHRISTIAN OCHEI}

Christian Ochei is an assistant professor of manufacturing and industrial technology at Cuyahoga Community College. He teaches CAD/CAM, computer programming and industrial technology classes and training courses.

\section{ROBERT RICE}

Robert Rice is completing his degree in mechanical engineering technology from Cuyahoga Community College in Spring 2001 and plans to continue for a bachelor's degree in University of Akron. Currently he is practicing as a production engineer in Solon, Ohio. 